\title{
Industrial Electronics for Biomedicine: A new Cancer Treatment using Electroporation
}

\begin{abstract}
Industrial electronics comprises a wide range of transversal and multidisciplinary technologies and applications that has been enabling human advance since the emerging of this scientific discipline in the XX century. Among the many present challenges, biomedical applications are one of the most challenging and rewarding ones due to the complexity and magnitude of the problems to be solved, and its inherent relation with the most important aspects in the human being hierarchy of needs: health and well-being.

Cancer treatment has become a major goal for the whole humanity due to the ability of this disease to affect in its many forms to all social collectives, despite age, gender or class, and its terrible consequences not only for the patient but also for the caregiver and close persons. Despite the many advances in the last decades, we are still in need of new and effective tools to prevent, treat, cure and palliate the effects of cancer in our society. In this context, electroporation has become a promising tool to fight against cancer which is based on applying short electric field pulses to the tissue to be treated to obtain the desired biological effects. Industrial electronics has and will have a significant impact in the research and clinical application of this technology by providing the required power electronic converters, control architectures, electromagnetic analysis and design, and measurement systems in a multidisciplinary context.

This paper aims to present the current state-of-the-art and future challenges of electroporation as a promising cancer treatment tool, where industrial electronics is called to play a key role. Firstly, industrial electronics applications in medicine and, specifically, pulsed power applications, are discussed. After that, the current status of cancer treatment and the fundamentals, historic evolution and biomedical applications of electroporation are reviewed, making special emphasis in the multidisciplinary approach required. After that, the different technologies to implement high-voltage generators are discussed, future perspectives are drawn and different applications with experimental evidence are presented. This paper concludes evidencing the importance of industrial electronics in electroporation-based cancer treatment, opening a new window for improved cancer treatments.
\end{abstract}

Index Terms - Electroporation, biomedical applications, high voltage generators, power electronics, cancer treatment. 

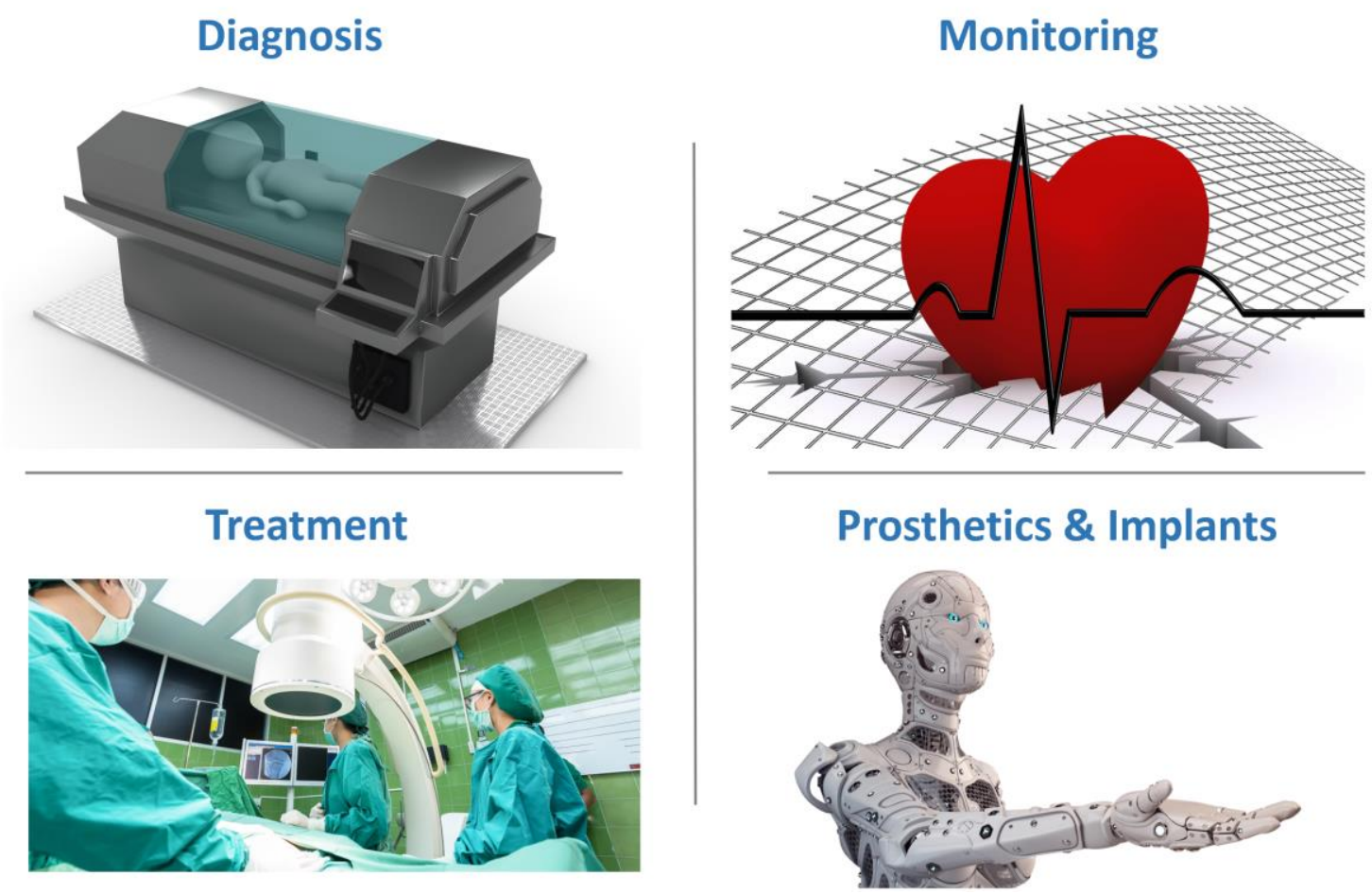

Fig. 1. Biomedical applications of industrial electronics.

\section{INTRODUCTION TO INDUSTRIAL ELECTRONICS IN BIOMEDICAL APPLICATIONS}

Industrial electronics (IE) plays currently a key role in biomedical applications, and with the many advances in the different enabling technologies, it is called to be a major facilitator for future and innovative treatments. This includes advances in different industrial electronics fields such as robotics, instrumentation, electronic sensing circuits, communications, or power electronics [1], among others. It is also remarkable that biomedical applications require a highly multidisciplinary approach, where IE acts as a unifying technology allowing the development of complex systems. In this context, a wide range of applications have been developed (Fig. 1), ranging from diagnosis and monitoring systems, to treatment, prosthetic, and implant systems.

Considering diagnosis and monitoring systems, IE has enabled the development of a wide range of ultrasound imaging [2], magnetic resonance [3] and X-ray [4] systems, which are among the most popular and widely used diagnosis systems. Monitoring systems for diabetes [5] and hypoglycemia [6] have also contributed to improve the quality of life of many people around the world. IE has also enabled the design of electromagnetic-based biomedical research systems [7], and arbitrary waveform generators for diagnosis [8].

Once the correct diagnosis is achieved, treatment is the next step where IE acts as a facilitator. Robotic systems [9] for surgical [10] procedures have started a revolution in surgical technology, enabling higher 
precision levels and remote procedures that were not possible before. Besides, electrosurgical systems [11] are routinely used daily around the globe, including electro-surgical generators for tissues cut and coagulation [12], or radio-frequency (RF) [13] and microwave (MW) [14] for ablation procedures. Controlled drug release [15] and electric stimulation [16, 17] systems are also representative examples of IE technology being applied to biomedical applications. Finally, nanoparticle heating systems are an example of power electronic systems applied to promising treatment techniques by means of controlled heating and/or drug release $[18,19]$.

Many times, after the treatments, different kinds of prosthetic and implants are required to recover functionality and improve the patient quality of life. In this context, miniaturization of power converters [20] and communications [21, 22] have enabled the design of highly portable and reliable implants. Robotic-aided movement [23] has also made possible to recover movement when one or several extremities are damaged or missing. Also, sensors [24] and alternative energy sources [25] and energy harvesting [26] systems have enabled the development of smarter and long-lasting electrified prothesis. In this sense, wireless power transfer systems [27-32] is a hot-topic research line as these systems have also permitted powering different kind of biomedical implants from cochlear to heart implants or data logging systems.

Among these applications, the use of pulsed power in medicine is one of the most relevant examples where IE plays a key role. Applications include a wide range of diagnosis and treatment systems where the pulsed energy is applied in many different ways. Firstly, mechanical energy is applied through ultrasoundgenerating systems that have been developed for both diagnostic [2] and treatment [33] applications, being one of the most common application fragmenting and disintegration of renal calculi (also termed kidney stones) . Electrical stimulators include a wide range of devices that can used for electric current stimulation, with applications such as muscle or neural tissue stimulation [34], or less-invasive magnetic field stimulation [35]. Pulsed radiofrequencies are applied for ablation or pain treatment [36] as well as for electrosurgery [37]. Higher pulsed electromagnetic energy is used for magnetic resonance [3] and X-ray [4] systems. Pulsed energy can also be applied in the form of light, being LASER use its main application. This technology has been mainly applied for precision surgery, becoming very popular in ophthalmology [38] where retinal laser photocoagulation is performed, or for less invasive surgery such as prostate ablations [39]. Pulsed electromagnetic fields (PEMF) are also applied to promote bone and cartilage regeneration. In this case, low energies are applied. The effect is non-thermal and the therapeutic effects result from a direct effect of the electromagnetic fields on the Adenosine receptor A2a. Finally, the application of pulsed electric fields results in biological tissue treatment through the induction of controlled and desired cell changes. Among these applications, electroporation and its applications to cancer treatment will be deeply discussed in this paper. 
These tools and techniques, and many others, are examples of the IE elements applied in medicine, with many of them involved in the long-lasting fight against cancer. The aim of this paper is to present electroporation (EP) as a relevant cancer treatment technique where industrial electronics plays a key role to develop modern and versatile systems. The current cancer status and electroporation techniques will be discussed in Section II, focusing also on the necessary multidisciplinary research. Section III will detail the state-of-the-art power electronic technologies applied to electroporation. Section IV will present the available electronic medical equipment for electroporation and an application example of an innovative system. Finally, Section V will draw the final remarks and future perspectives for EP.

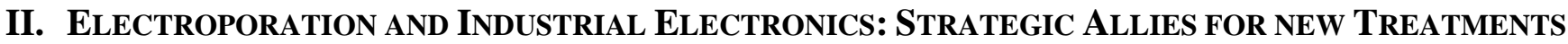

\section{A. Cancer: In Need of new Treatments}

Cancer is the general name given to a collection of related diseases. All of them have in common that a certain group of cells begin to divide without control, and spread into other tissues, surrounding or far from the primary starting point. It usually creates important functional disorders and eventually leads to the patient death. According to the World Health Organization (WHO), nowadays cancer has become the second death cause in developed countries, only after hearth failures. Moreover, world statistics predicted by the American Cancer Society (Fig. 2) foresees a 50\% increase in worldwide new cases, up to 21 million per year, and $60 \%$ deaths increase, up to 13 million. Considering this scenario, cancer prevention, diagnosis, and treatment have become priorities in our modern societies with a huge socio-economic impact.

CANCER STATISTICS 2012 to 2030
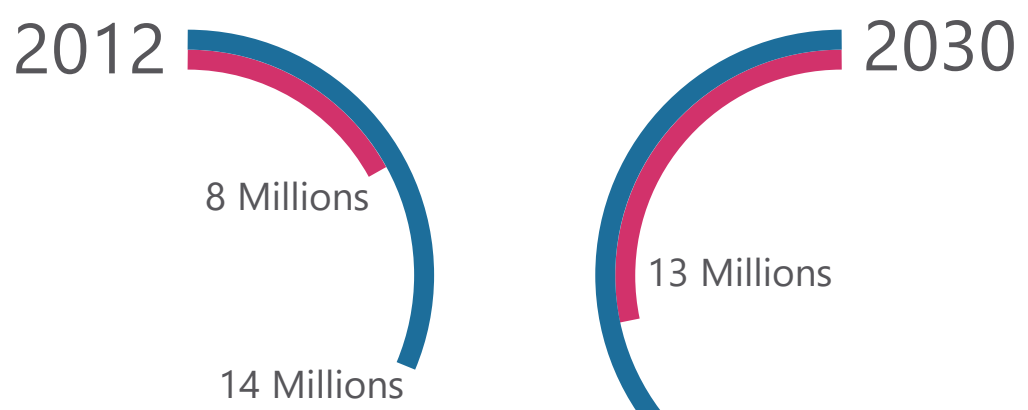

21 Millions

Worldwide cases: $\quad+50 \%$ Increase

Worldwide deaths: $+60 \%$ Increase

Fig. 2. Predicted cancer evolution (Source: American Cancer Society, cancer.gov). 
Nowadays, the main treatments against cancer (Fig. 3) include surgical resection, radiofrequency (RF) or microwave (MW) ablation, chemotherapy, radiation therapy, immunotherapy and modern targeted therapies. All of them can be used alone or in combination to try to reach patient cure or cancer and sideeffect symptoms alleviation, and they are briefly discussed in the following lines.

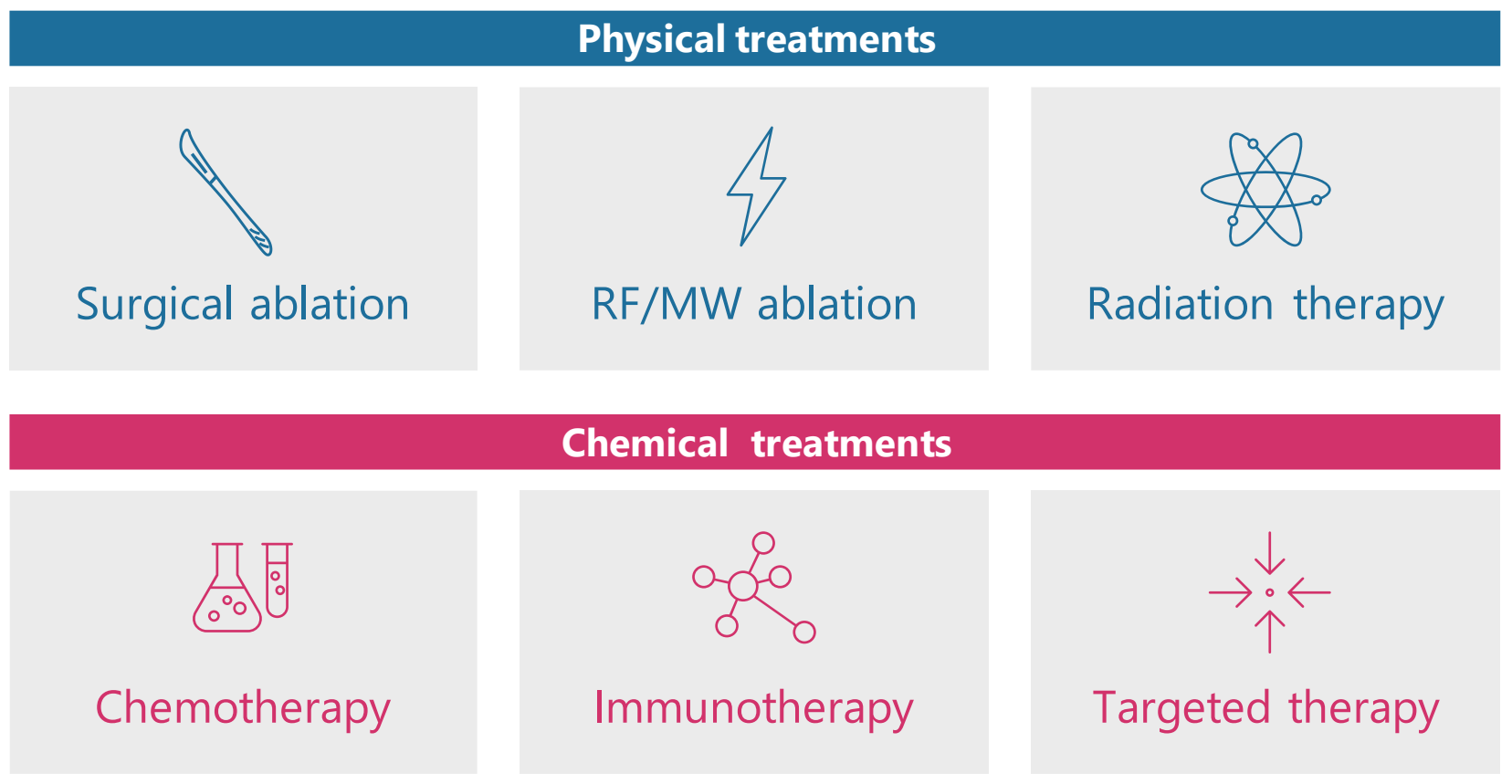

Fig. 3. State-of-the-art cancer treatments.

Surgical resection, when possible, is still the primary treatment for most cancer cases. It consists in removing the tumoral tissue using surgical procedures. After that, the obtained tissue is analyzed to ensure that the contour is free of tumor cells to minimize the possibilities of relapse. Despite being curative in many cases, it cannot be applied in those cases where the tumor localization cannot be easily accessed, or the affected region is too irrigated and/or contains vital structures that need to be preserved. Modern alternatives to this procedure are RF or MW ablation [40]. These are thermal techniques based on increasing locally the temperature in order to kill the cells of the area to be treated. The main challenge of these techniques is to ensure that the tumor has been completely covered by a sufficient temperature increase, especially due to the cooling of blood irrigation. Because of this, these methods are prone to tumor relapse. The last treatment in the group of physical treatments commonly applied is radiation therapy, based on selectively applying radiation to the tissue volumes to be destroyed. This technique provides easier access to zones difficult to be treated, but it is seldom curative, and it is commonly used in combination with other treatments or to alleviate cancer symptoms. Within these physical treatments, IE is a key enabling technology to build electrosurgical, ablation, and radiotherapy systems.

Chemical agents are also used to treat cancer, being chemotherapy a very usual one nowadays just after 
surgery. Chemotherapy uses drugs to kill fast-growing cells with the important benefit of acting throughout the whole body. It is used to try to achieve curation, control of cancer growth or alleviate symptoms, usually in combination with other physical treatments. Despite its benefits, its success rate is still rather low and highly dependent on the patient, and can have important side effects due to its inherent toxicity. Modern chemical treatments include also immunotherapy and targeted therapies. Immunotherapy consists on using the patient's immune system to fight cancer either by stimulating it or by providing external immune agents, e.g. monoclonal antibodies. Despite being an alternative to chemotherapy with far less side effects, the effectivity is still insufficient, and more research is required. Finally, targeted cancer therapies use drugs specially designed to affect growth and spread of cancer by interfering with specific molecules present in cancer tissue. Unlike standard chemotherapy, it does not affect to normal fast-growing cells, providing a more effective treatment and less side effects. However, it still requires major research efforts to identify and exploit molecular targets for a wider variety type of cancers.

As a conclusion, nowadays there is a wide range of cancer treatments being applied, taking advantage of different advances in key enabling technologies in many areas, where IE plays a key role in some of them. However, none of them still offers a perfect solution that can be applied to all types of cancer and patients. For this reason and considering the major socio-economic relevance of this topic in our society, it is essential to investigate new treatments to provide additional tools against cancer. In this context, electroporation arises as a new and promising therapy able to treat cancer in those cases where electroporation-based treatments possess advantages such as fewer side effects and lower costs (both, in the materials, e.g. devices, drugs, and in human working forces for exploitation, control, and maintenance), and in cases where classical techniques cannot be applied. Next subsection discusses basic elements of electroporation, applications, and its related power electronics technology.

\section{B. Fundamentals of electroporation}

Electroporation consists on applying intense and short electric field pulses to biological tissues in order to cause cell membrane permeabilization, leading to different effects depending on the electric field parameters [41].

The main interaction between the electric field and cell membrane translates in an induced voltage that is added to the "natural" resting transmembrane voltage present in all cell types. Theoretical descriptions have predicted the dependency of this induced transmembrane voltage on the frequency, duration or intensity of the applied electric field according to Schwan equation [42]. Fundamental studies have demonstrated that if this induced voltage exceeds a threshold value (estimated in the order of a few hundreds of $\mathrm{mV}$ across the membrane), electroporation is triggered. The underlying molecular mechanisms of electroporation are still unknown and are nowadays investigated by many groups. The most accepted theory explains the increased 
permeabilization state in the cell membrane by a change in the lipid structure due to the penetration of water in the inner parts of the membrane during electric field exposure, with the subsequent generation of hydrophilic pores. Molecular dynamics, an in silico investigational approach has brought a number of insights on this process supporting this theory [43]. Experimental evidences are still to come.

If the applied electric field is strong enough, the process leads to a permanent cell membrane disruption and thus the cell death. This is called irreversible electroporation (IRE). On the contrary, if the electric field does not reach the IRE threshold, the cell is able to recover and to come back to its previous state, and the process is called reversible electroporation (RE). IRE is commonly used as a method to kill cells, whereas $\mathrm{RE}$ is used to permeabilize the tissue and facilitate the interchange (incorporation or externalization) of molecules across the membrane. Fig. 4 shows an example of RE and IRE application to a mammalian cell.

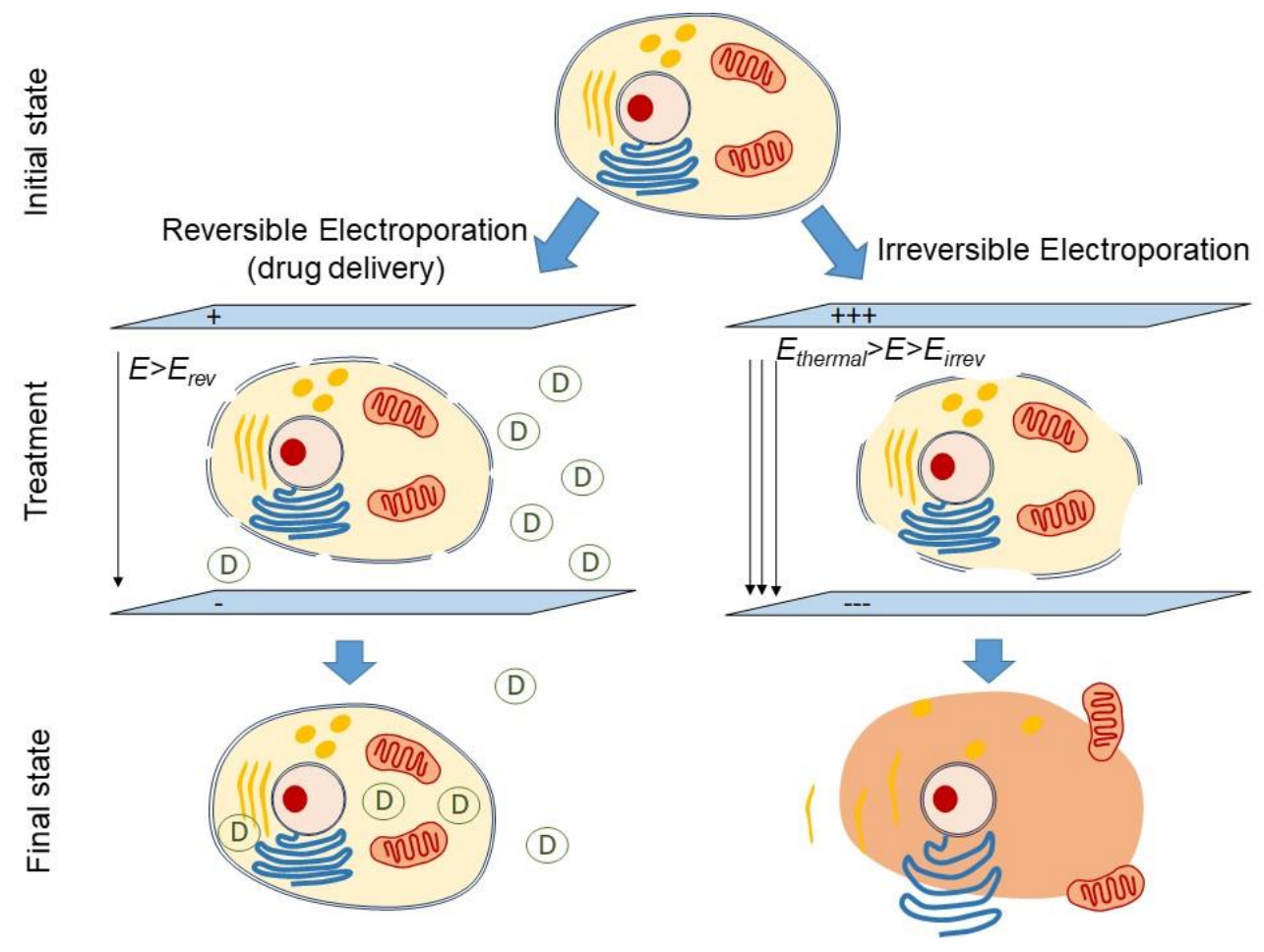

Fig. 4. Electroporation: reversible (left) and irreversible (right) processes [44].

The three basic elements of any electroporation treatment are then: 1) the biological sample under treatment that can range from single cells to whole tissues both from animal or plant origin; 2) the application electrodes, which is the part of the system responsible for the electric field delivery and 3) the electric field generator, which is the electronic system responsible of generating and controlling the electric field to be applied.

Regarding the characteristics of the electric field pulses applied, there is a wide range of possible values that have been used in the literature and that need to be adjusted depending on the application [45, 46]. In [47], a detailed review of the pulses used in clinical studies is made. In general, the electric field intensities 
range from some hundreds of $\mathrm{V} / \mathrm{cm}$ up to several tens $\mathrm{kV} / \mathrm{cm}$, with pulse duration ranging from few ns to hundreds of $\mu$ s. These two parameters are highly correlated and a reduction in one of them is translated into an increase in the other for achieving a similar effect. Other additional parameters as the waveform used are discussed in the next section.

\section{Electroporation Applications for Cancer Treatment}

Electroporation phenomena were initially described by J.A. Nollet in 1754 [48], where the effects of electric sparks into human and animal skin was described. After that, during the XIX century there was a in increasing interest on the research of the uses of electricity, although most of them were thermal and electroporation was not explicitly cited [49]. During the XX century, there was a renewed interest in applications of electricity in medicine. Initially, most of the research was focused to reversible electroporation, where applications to cell fusion in 1989 [50] and electrochemotherapy in 1991 were described [51-53]. Later, at the beginning of the XX century, the interest in IRE increased and it was described as an ablating method for tumors [49]. Since then, a significant number of clinical applications of IRE to tumor ablation [47] and RE to electrochemotherapy [54] have been reported.

In the last decade, applications of electroporation have spread from alimentary applications, such as food processing [55] and disinfection [56, 57], to biomedical applications, such as gene transfection [58], electrochemotherapy [59] or tissue ablation [60]. This paper will focus on biomedical applications of electroporation for cancer treatment, and the industrial electronics technology enabling these techniques, which is discussed in the next subsection.

The potential applications of electroporation in cancer treatment are the reason behind the growing interest of many research groups around the world. Both modalities of electroporation (reversible and irreversible) are successfully used in the treatment of cancer with differentiated mechanisms of action (Fig. 5). One of the main advantages of electroporation is that it is a general phenomenon applicable to all cell types, what enables its use in very different cancer types. Here below, the two main applications of electroporation to cancer treatment, and their advantages, are explained in detail. Additionally, other electroporation-related approaches against cancer are also explained. 


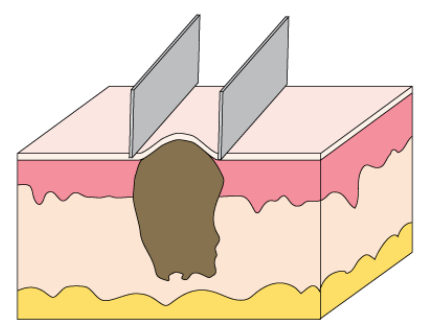

(a)

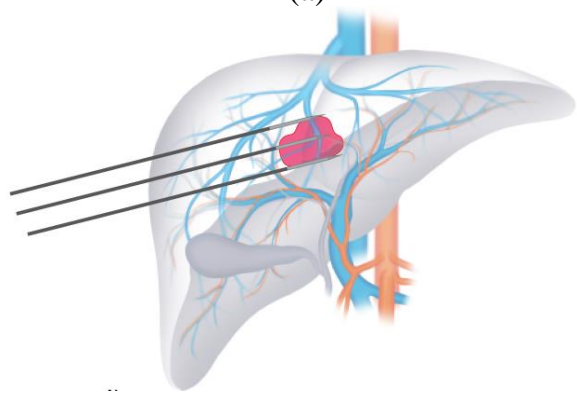

(c)

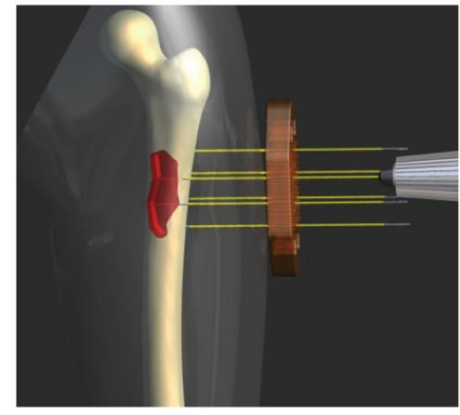

(b)

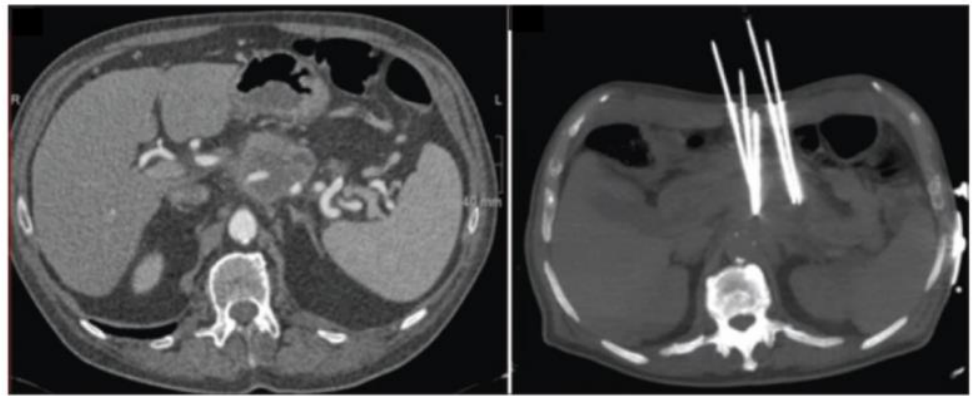

(d)

Fig. 5. Examples of clinical applications of electroporation. a) Schematic representation of the treatment of superficial skin cancers with non-invasive plate electrodes. b) Example of bone metastases treatment with needle electrodes (adapted from [61]). c) Schematic representation of needle electrodes placed around a tumour in the liver. d) Computed tomography images of a pancreatic tumor and the inserted needles for treatment by irreversible electroporation (reproduced from [62]).

IRE tissue ablation. As previously explained, when the parameters of the electric pulses exceed a certain threshold, the electric field exposure leads to cell death. Usually, trains of about 80 electric pulses of about $100 \mu \mathrm{s}$ at relatively low repetition frequencies, hundreds of ms, are employed [63, 64]. This procedure is used as a focal ablation technique to locally eliminate the exposed cancer tissue [60]. However, unlike other thermal ablation techniques, it has been demonstrated that cell death caused by irreversible electroporation is not based on a thermal effect. For this reason, IRE is not affected by the heatsink effect of blood perfusion, so a more controlled tissue ablation can be done. Additionally, another important advantage of IRE over other techniques is that part of the cell deaths observed is caused by apoptosis and not only by necrosis [65], which leads to a less harmful process and a faster recovery. Besides, tissue structures, like nerves and blood vessels, are kept functional after treatment. For this reason, IRE can be applied in areas where surgery or thermal ablation are not applicable. Since it is a fast treatment, it can also be applied several times to ensure its effectivity and prevent tumor relapse.

Nowadays, IRE is used in the clinical practice to treat different types of internal cancer with success rates similar to the competing techniques. Its efficacy and safety have been assessed for a number of different cancer types like liver, lung, pancreatic, prostate, etc. [66]. For example, in the case of pancreatic cancer, this is promising technique due to the preservation of important structures around tumor tissue, however its 
efficacy is still limited [67]. Currently, different strategies have been proposed to improve the efficacy and facilitate the applicability of IRE. Among these, proper treatment planning assisted by electromagnetic simulations, image-guided electrodes positioning [68] or reduction in the undesired effects of IRE using new modulation patterns [69] are under development. These improvements will help promoting the establishment of IRE as a first treatment option in the future.

Electrochemotherapy. The antitumor electrochemotherapy (ECT) was the first clinical application of the electroporation [51]. It consists in the combined use of hydrophilic cytotoxic drugs and electric pulses. Usually, 8 electric pulses of $100 \mu \mathrm{s}$ and $1300 \mathrm{~V} / \mathrm{cm}$ transcutaneous pulses are applied, or $1000 \mathrm{~V} / \mathrm{cm}$ pulses delivered through invasive needles, at a repetition frequency of 1 or $5000 \mathrm{~Hz}$ [70, 71]. The electric pulses are delivered to cause the reversible electroporation of the cells, offering the hydrophilic drugs the possibility to enter the cells and kill them. Bleomycin is the preferred drug because of its difficulties to enter the cells in the absence of the cell membrane (electro)permeabilization [72]. Bleomycin is also very interesting to use because it kills only the cells that divide, therefore mainly the tumor cells inside the volume exposed to the reversibly permeabilizing electric pulses. Therefore, if bleomycin is administered intravenously [70,71], the margins of the tumors can be safely and conveniently treated, preventing further local recurrences.

ECT can be applied both for internal and superficial (cutaneous and subcutaneous) tumors, with excellent aesthetic results (due to the very low toxicity on the normal tissues). Efficacy of the ECT is also due to the effects of the electric pulses on the neovascularization of the tumors (the pulses cause a transient vascular lock).

Effectiveness of the ECT is also due to the fact that the combination of the electric pulses and bleomycin causes what is called an immunogenic cell death [73], which means that the direct effect of the electric pulses plus bleomycin combination is able to wake up the immune system of the host. The combination of ECT and immunotherapy can result in a very efficient and safe systemic treatment of the cancer (while the ECT alone is only a local treatment) [74]. However, ECT, with respect to the other local ablative treatments like surgery, IRE, ablathermia, and even radiotherapy, is not just an ablative procedure as it is able to respect the normal cells located in the treated volume, allowing also for a safer and larger convenient treatment of the margins. Thus ECT use is expanding in the EU and elsewhere, and its use is also rapidly progressing in the veterinary clinics [75].

Other applications in cancer. Other applications of electroporation in cancer treatment include genetransfer related procedures. The spontaneous uptake of nucleic acids (which are hydrophilic molecules, like Bleomycin) by cells in vitro is almost inexistent and in vivo extremely reduced [76]. The use of electroporation for gene transfer in vivo was initiated 20 years ago, using 8 or 10 long pulses of 5 ms [77] 
or $20 \mathrm{~ms}$ [78] duration. For tumor treatment, two approaches emerged, the electrotransfer of the gene coding for a cytokine (a protein active in the immune system) like the interleukin 12, or the transfer of a gene coding for a tumor specific protein against which the body will "vaccinate" (that is, develop a specific immune response that will destroy the cells exposing this protein, therefore the tumor cells). The IL-12 electrogene transfer has been already employed in clinical trials to treat human [79] and animal [80] patients. Electroporation is very attractive to be used as a delivery method for DNA-based vaccines [81, 82]. The DNA vaccine is injected intradermally, intramuscularly or intratumoraly followed by the application of the electric pulses (usually with duration in the millisecond range), resulting in the intracellular uptake of the vaccine and subsequent gene expression [83]. The safety and the economical reduction of this treatment as well as the possibility of repeated administrations make this technique an attracting possibility that has been already used in preclinical and clinical studies [83].

\section{Synergetic multidisciplinary research}

In order to address the significant challenge of cancer treatment by means of electroporation, it is evident that a multicisciplinary approach was needed. This research involved several different research areas, usually distant, not well communicated and with very different working methodologies, including, but not limited to, electrical, biomedical and materials engineering, biology and histopathology, radiology and interventional radiology, surgery, among others. All these research areas provided different point of views to the same problem and shared the same objective, providing a common global view to guide the research process. This helped and will continue to help leading the research process towards complete electroporation systems which not only satisfy the electrotechnical specifications, typically the area of interest of IE, but also ensure the treatment correct application, the ergonomy and safety for both the patient and medical staff, the optimization of the desired biological outcomes and the achievement of a sustainable therapy that can be implemented considering not only technical and biomedical results, but also logistic and cost considerations. Besides, and since this is a clinically oriented multidisciplinary research, there are significant bio-ethical considerations that must be carefully addressed regarding animal tests and, the final goal, the treatment of human beings for cancer cure/mitigation. Only when all these aspects are carefully considered and the multidisciplinary team shares a clear common goal, the synergies between the teams can come to positive results for a complex problem in a complex working environment.

\section{High VOLTAGE GENERATORS FOR ELECTROPORATION}

Generation of complex waveforms has been a necessity for many medical applications [8]. Electroporation is not an exception, and it requires high voltage generators in order to generate the required 
electric field to perform either RE or IRE processes [84].

As mentioned before, electroporation outcomes change significantly with the parameters of the applied electric field. Consequently, there are certain characteristics that high voltage generators in this field must fulfill. Fig. 6 summarizes the main characteristics desired for modern high-voltage generators for electroporation.

\section{Isolation}

\section{Pulse}

- Amplitude

- Bipolarity

- Width

- Arbitrary waveform

- Output Z

\section{Modularity}

Fig. 6. Desired features for high voltage generators for electroporation applications.

Firstly, generators are generally required to operate under electric isolation to provide safe treatment for both the practitioners and the patients in order to avoid the hazard of electric shock or interference with other equipment. Also, it is desirable to be modular to be scalable and easily integrated into the whole operating room equipment.

As described before, regarding the pulse characteristics, a wide range of intensities and durations can be used. Moreover, some specific applications of electroporation, such as gene transfection, require the dynamic modification of the intensity of the applied field in order to optimize the procedure. For this reason, it is essential that the generator can accommodate a wide range of output voltages, being typically at least in the range of several $\mathrm{kV}$ coupled to high output currents of tens of amps or more. In addition to this, pulse width has also an important effect on the whole electroporation process. Typically, pulse width is set to be in the range of hundreds of $\mu$ s. However, recent studies have proposed the use of shorter pulses, in the range of one or a few $\mu$ s, in order to reduce undesired muscle stimulation, being this technique called H-FIRE [69]. Also, millisecond pulses alone or in combination with $\mu$ s pulses are routinely used for gene electrotransfer [85]. Finally, nanosecond range pulses have also been extensively used in the field of electroporation [86]. For this reason, fast power devices are also required. Last, but not least, the output impedance of the generator is an important parameter, since it determines the effective electric field applied to the load and, consequently, the treatment repeatability and effectiveness. For this reason, it is desirable to 
have an output impedance as low as possible that guarantees a stable and controlled electric field applied. As it will be later discussed, it is not always possible for all the technologies and employed loads.

The typical waveforms of the voltage pulses that are usually applied during electroporation processes are summarized in Fig. 7. Nowadays, many EP processes use exponential-decay pulses (Fig. 7 (a)), especially when fast pulses or very high voltages are required. This approach started with early developed generators which were based on Marx generators. With the advance of the technology, square wave pulses were preferred (Fig. 7(b)), since the time above a certain electric field threshold is important and can be controlled in a very precise way, while the dynamics of the rise and fall times, which are determined by the switching devices and topology (and usually limited due to EMC issues), does not usually impact on pulses efficacy [87].

Considering square-wave voltage, it was later determined that bipolar pulses (Fig. 7 (c)) are interesting in order to ensure zero mean output voltage value and prevent electrolysis effects, which may degrade electrodes and the tissue under treatment. This led to the use of inverter power converters able to provide bipolar output voltage. Finally, in some applications, in order to improve the effectivity of EP and reduce treatment time, pulses can be arranged in bipolar train of pulses (Fig. 7 (d)). These are limited by the total delivered energy, and the time between trains of pulses is chosen to avoid any thermal effect.

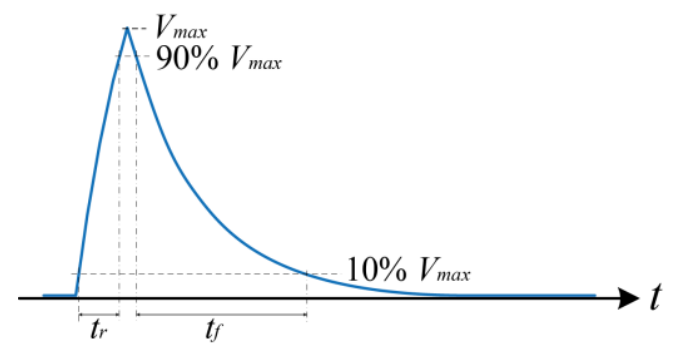

(a)

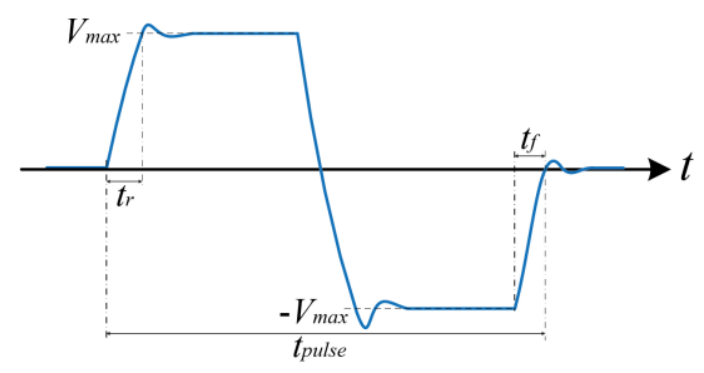

(c)

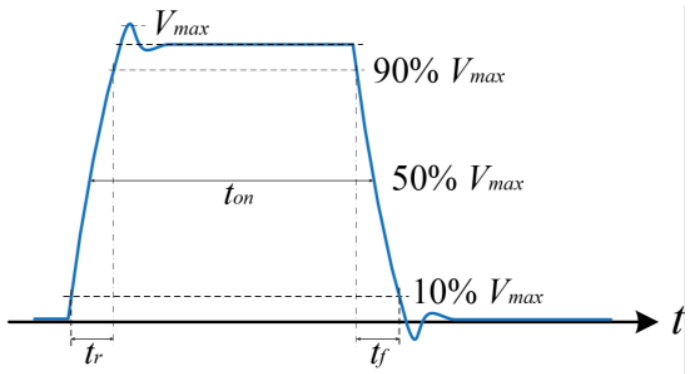

(b)

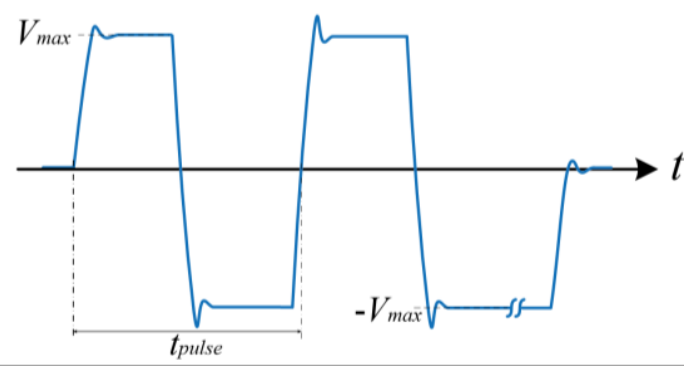

(d)

Fig. 7.Typical pulses applied in electroporation: (a) exponential decay (capacitor discharge), (b) square-wave pulse, (c) bipolar square-wave pulse, and (d) bipolar train of pulses. 
In the past, several families of high-voltage generators for EP have been proposed (Fig. 8). These can be classified into transformer-based inverters, capacitor-based inverters, and resonant inverters.

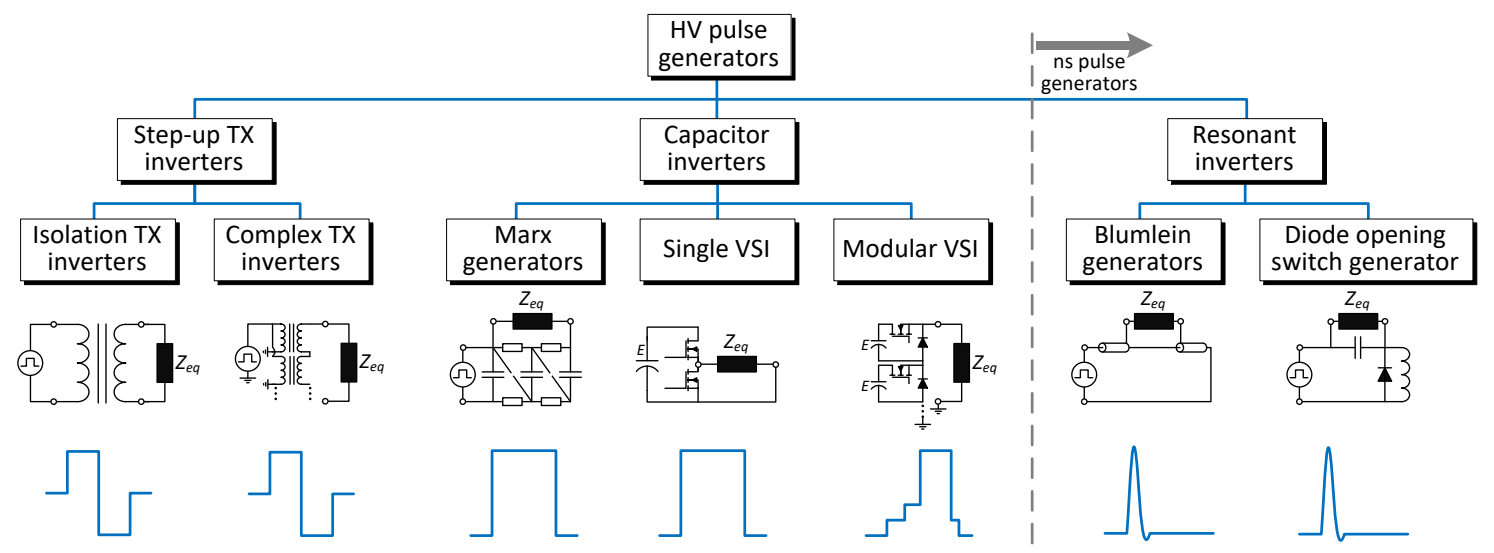

\begin{tabular}{|c|c|c|c|c|c|c|c|}
\hline Isolation & Yes & Yes & No & No & No & No & No \\
\hline Amplitude & Yes & Yes & No & Yes & Yes & No & No \\
\hline$\overline{\text { Bipolar }}$ & Yes & Yes & No & No & No & No & No \\
\hline Width & $\mathbf{Y} / \mathbf{N}$ & $\mathbf{Y} / \mathbf{N}$ & No & Yes & $\mathbf{Y} / \mathrm{N}$ & No & No \\
\hline Arbitrary & No & No & No & No & Yes & No & No \\
\hline Output $Z$ & $\bar{M}$ & $\mathrm{M}$ & L-M & $\mathbf{L}$ & $\overline{\mathrm{L} / \mathrm{H}}$ & $\overline{\mathrm{H}}$ & $\overline{\mathrm{H}}$ \\
\hline Modularity & No & Yes & Yes & No & Yes & No & No \\
\hline
\end{tabular}

Fig. 8. High-voltage generators summary and comparison. The three main families, transformer-based (TX), capacitor-based and resonant topologies, are compared. The main desired features for electroporation are considered including isolation capabilities, pulse amplitude control, bipolar operation, pulse width control and arbitrary waveform generation, output impedance (high/medium/low) and modularity.

The first group of converters, transformer-based inverters, relies on the use of a transformer to provide both isolation and voltage boost (Fig. 9). These converters can easily reach high voltages [88] and, for this, reason, these are commonly used for those applications that require the highest applied field amplitudes, e.g. food processing or disinfection. However, due to the use of the transformer (Fig. 9(a)), these topologies cannot generate arbitrary waveforms, and they are limited to a narrow operating range, i.e. amplitude and frequency, in which they are designed for. Another important limitation is that the output impedance is determined by the transformer (Fig. 9(b)). This leads usually to a high impedance that, depending on the load, may degrade the output voltage waveform, leading to non-predictable electroporation results (Fig. 9(c)). For these reasons, this family of generators is gradually being dropped from biomedical applications and only used on very high voltage applications. 


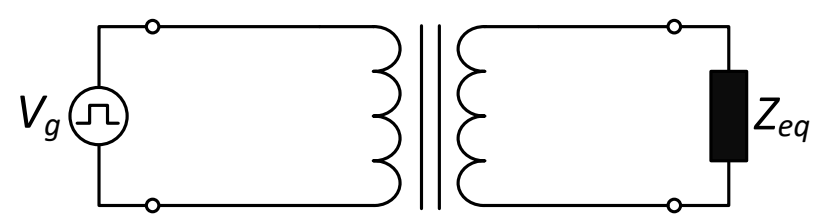

(a)

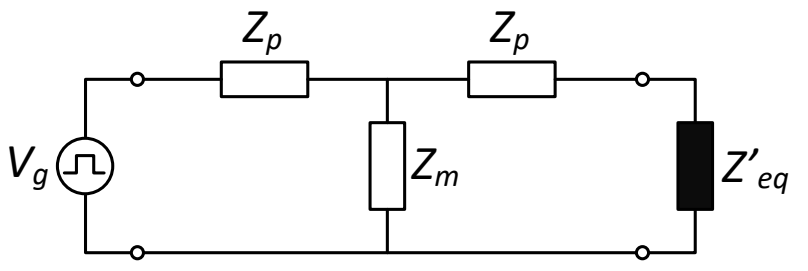

(b)

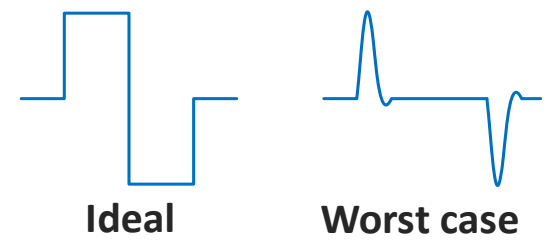

(c)

Fig. 9. Transformer-based high voltage generators for electroporation: (a) general approach, (b) input/output impedance detail, and (c) output waveforms.

Capacitor-based inverters are the second family of converters (Fig. 10(a)). These converters use a capacitor bank to store the energy plus an inverter to provide unipolar/bipolar output voltage. Several topologies have been applied, including Marx generators, single-stage voltage source inverters, or modular multi-level approaches [44, 89-91]. The main challenge when using this approach is to achieve very high output voltage, which may require the use of multi-level topologies and high-voltage power devices, as well as the appropriate design of the energy storage system. Otherwise, the exponential-decay voltage waveform previously discussed (Fig. 10(b)) would be generated in the worst-case condition.

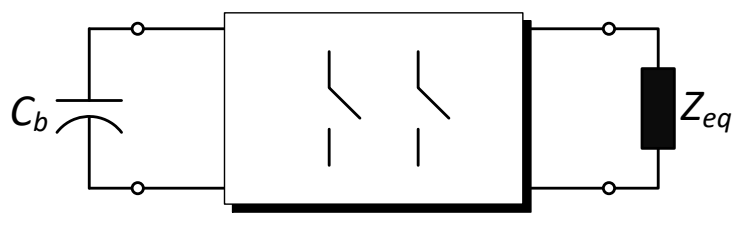

(a)

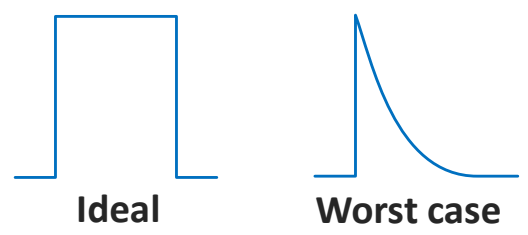

(b)

Fig. 10. Capacitor-based high voltage generators for electroporation: (a) general approach, and (b) output waveforms. 
Finally, as mentioned before, some special applications of EP require the generation of high voltages during few nanoseconds. For these applications, resonant or quasi-resonant topologies are usually applied, providing high voltage gain in a simple manner. Different topologies have been studied in the past for nano-second EP generators [92, 93], including also Marx generators or Blumlein networks [94]. The main drawbacks of these topologies are that they do not provide isolation and there is no or little control to the output voltage due to the high output impedance and effect of parasitic elements.

\section{MEDICAL ELECTRONIC EQUIPMENT FOR ELECTROPORATION}

\section{A. Electroporation pulse generators}

As it has been previously discussed, IRE generators require a number of desired features to be used in a flexible way during research and clinical procedures. Nowadays, commercially available generators for biomedical applications of electroporation [95] follow the capacitor-based approach, and can be classified into two groups. Firstly, generators for in vitro processing of tissue uses usually the capacitor-discharge technique, being able to deliver up to $3 \mathrm{kV}$ and few amps, with a discharging capacitance in the range of few $\mathrm{mF}$. On the other hand, generators for clinical applications are designed to operate with the same voltage, i.e. $3 \mathrm{kV}$, limited usually by the power devices, but higher current capabilities, up to 50 A [96].

Despite the availability of commercial generators, there is a wide gap for innovation and improvements such as improved voltage and current ratings, versatility of the output waveform, and quality of the output signal. Considering this background, next subsection presents an application example where a highly versatile generator has been designed, implemented and tested for high-volume liver IRE ablations.

\section{B. Electrodes}

Electrodes for tissue electroporation are based mainly in two geometries [84]: parallel-plate and needle electrodes. The former achieves homogeneous electric fields whereas the latter provide higher versatility for in-vivo applications. Parallel-plate electrodes are consequently used in those cases where electric field homogeneity is essential and a very easy accessibility to the tissue to be electroporated achievable. For these reasons, this geometry is often limited to in-vitro electroporation and certain in-vivo superficial electroporation as in the treatment of small cutaneous tumor nodules [97]. In spite of these restrictions, recent studies have also shown the application of these structures to internal organs such as liver [98] or pancreas [99] during intraoperative procedures.

Despite inhomogeneity issues [100], needle electrodes are the preferred electroporation electrodes for large as well as for subcutaneous and internal organs because they are minimally invasive [84]. These electrodes can be applied percutaneously, with the help of imaging systems to avoid damaging vital 
structures, or during open surgery. Commonly, when tumor nodules are large, several needle repositioning are required to cover the whole tumor area [101]. Alternatively, large electrode arrays can also be used [102].

Advanced and modern trends in electrode design are aimed to improve the effectiveness of the electroporation process and to simplify it. Among the most promising developments, it is worth noticing the design of needle-based arrays able to cover wider areas in a single treatment [103], comb-shaped electrodes to reduce the required voltage for IRE [104], or the design of single-needle bipolar electrodes to minimize the number of required needle insertions [105].

\section{Application example: Large-volume in-vivo IRE ablation}

Considering the previously discussed IRE considerations and technical requirements, a new versatile high-voltage generator for electroporation was designed and built [44]. The proposed generator features a versatile multi-level structure that enables obtaining up to $10 \mathrm{kVpp}$ and $400 \mathrm{App}$ with the benefits of using a voltage-source inverter, i.e. low output impedance. Besides, its FPGA-based control architecture provides full control flexibility, enabling configurable pulse shape.

Nowadays, the commercially available solutions for clinical applications in humans are mainly restricted to the Nanoknife $@$ generator (Angiodynamics, USA) for the IRE and the Cliniporator@ generator (IGEA, Italy) for the Electrochemotherapy and the gene electrotransfer. In veterinary medicine, the ELECTROvet EZ (Leroy Biotech, France), the OnkoDisruptor (Biopulse, Italy), the VET CP 125 (Vet Câncer, Brazil), among others, are also used to treat tumors in dogs, cats and equines. In addition to this, several commercial systems are available for cells electroporation in vitro, i.e. in cuvettes (BTX, Leroy Biotech, Eppendorf, Bio-Rad, among others), that provide suitable test-benches for research and small-scale production. However, all these systems are typically limited to $3 \mathrm{kV}$ and few tens of amps. Besides, control capabilities as well as bipolar voltage generation are often unavailable. For these reasons, the proposed converter enables the improvement of the current state-of-the-art generators and opens the window for new IRE techniques. Currently, research efforts are being oriented towards the development of generators with improved waveform versatility [106], higher voltage [107], and frequency [108] capabilities.

The proposed generator is currently being used in the study of the ablation of large portions of liver tissue [109], not possible before with the current technology [98]. These tests performed in the Aragon Center for Biomedical Research were approved and followed all the stablished ethical procedures. Fig. 11 shows a general view of the experimental prototype (a), detailing the power converter composed of 1 control board, 1 bus-charge board and 5 bipolar 1-kV output modules, and (b) the parallel-plate electrodes used during pig liver IRE experiments. 


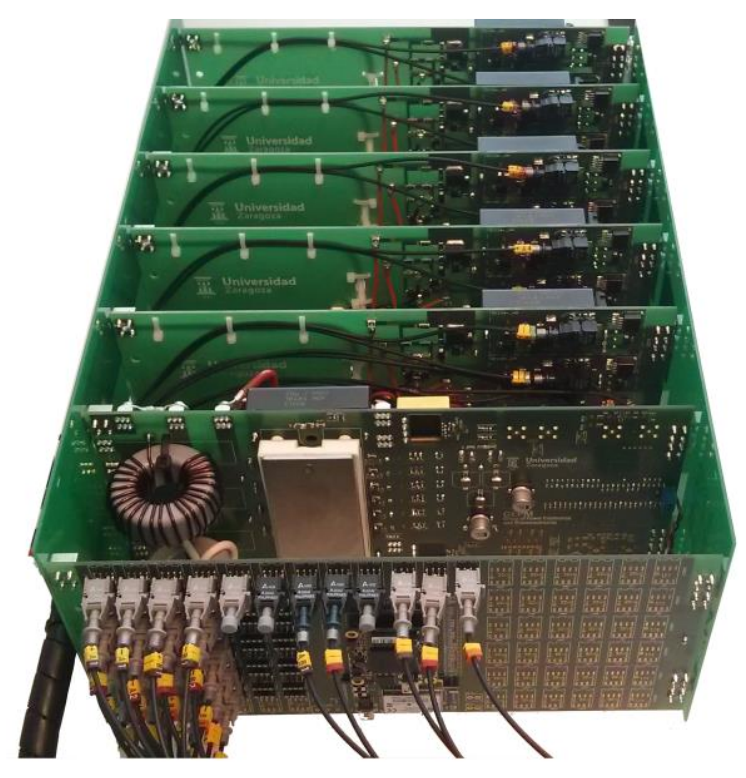

(a)

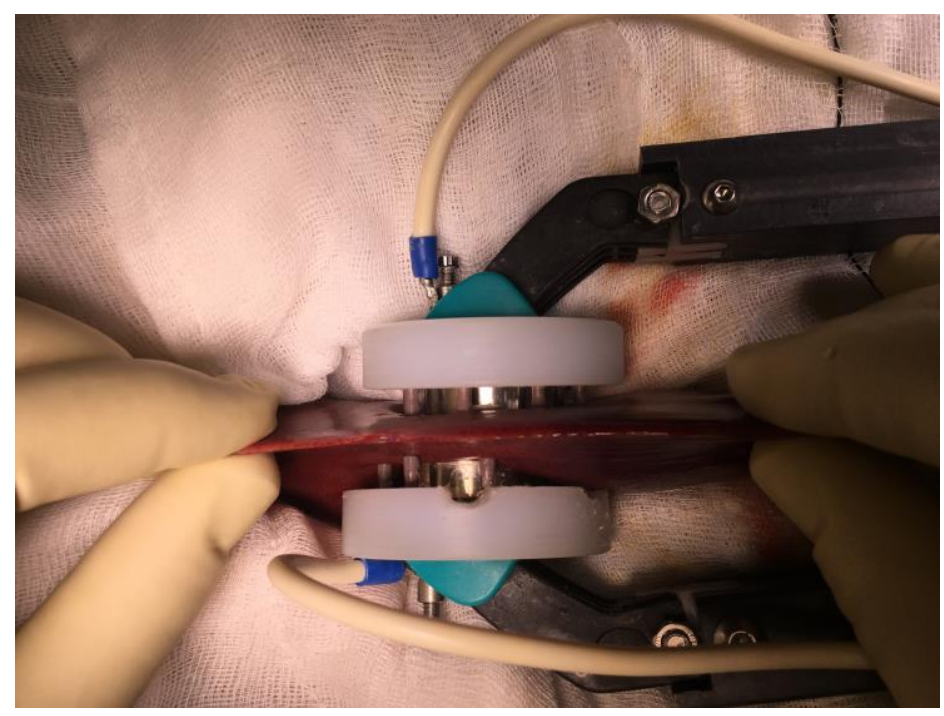

(b)

Fig. 11. Experimental prototype: (a) 10-kV output voltage versatile generator and (b) 3-cm parallel-plate electrode placed in the liver tissue to be treated.

Different representative waveforms of the electroporation process are shown in Fig. 12. In (a), several unipolar pulses are detailed, whereas in (b), a typical train of bipolar pulses in order to avoid electrolysis is represented.

The performed experiments proved the feasibility of the proposed converter for IRE applications. In a wider sense, this development is an example of the relevance of industrial electronics for biomedical applications and the potential benefits for society arising from synergies between industrial electronics and biomedical research. 


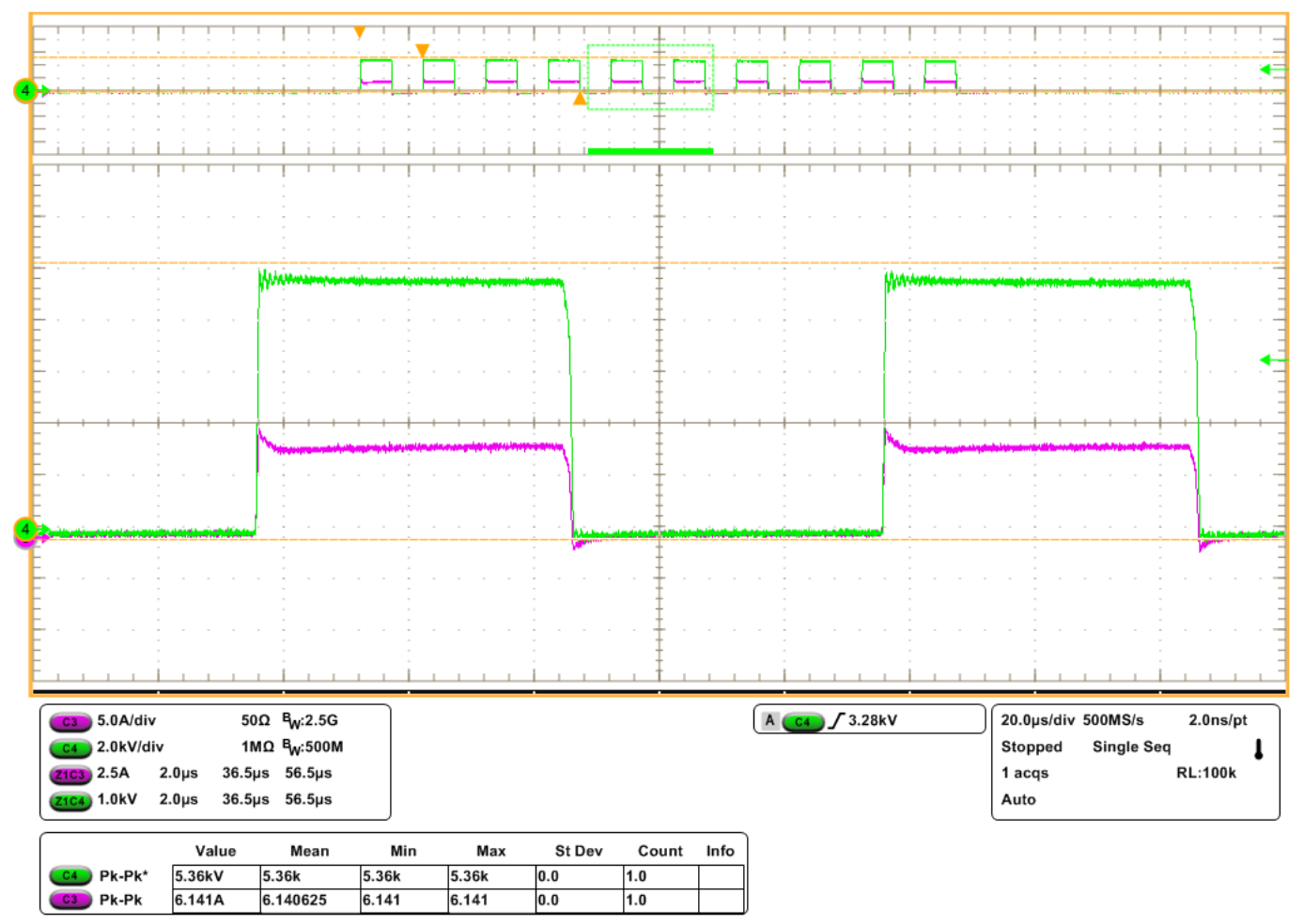

(a)

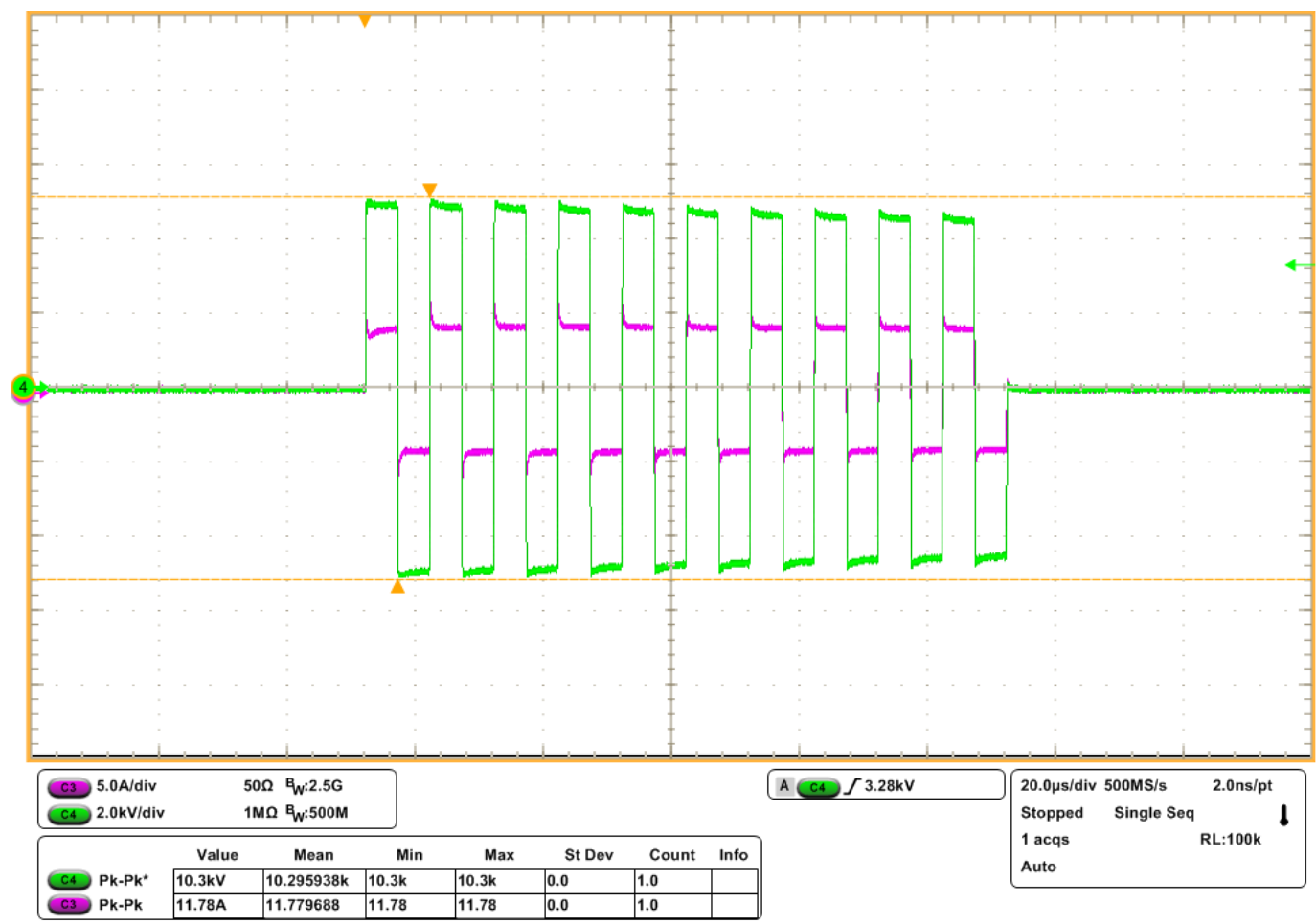

(b)

Fig. 12. Main waveforms during in-vivo electroporation in pig liver tissue: (a) Unipolar modulation and (b) Bipolar modulation. From top to bottom: Output voltage $(2 \mathrm{kV} /$ div) and output current $(5 \mathrm{~A} / \mathrm{div})$. 


\section{FinAl REMARKS}

This paper has reviewed a relevant application of industrial electronics applied to biomedical applications, making special emphasis in the potential benefits and necessary collaboration between industrial electronics specialists and medical practitioners. As it has been previously discussed, design of high voltage generators for electroporation is a challenging task due to the high requirements in terms of voltage amplitude, controllability, isolation, and output impedance. Nowadays, electroporation has already been acknowledge as a key tool for cancer treatment [110, 111] with growing importance, despite significant challenges must still be faced [112]. The future of this technology will require the development of versatile generators [44] that overcome all these limitations and provide useful tools for research, laboratory and clinical treatments. To achieve this goal, several industrial electronics technologies will play a key role. Research on advanced topologies will be essential, as well as the use of faster and higher voltage devices, such as silicon carbide and gallium nitride devices [113]. Also, advanced control architectures and strategies [114] will be required in order to accurately control the generator, monitor and optimize the treatment, and guarantee the safety for both the patient and the medical team. Considering this context, there is a brilliant future for industrial electronics technology applied to electroporation to be seen in the years to come.

\section{REFERENCES}

[1] B. Grzesik and M. Stepien, "Power electronics in biomedical applications - An overview," in Power Electronics and Motion Control Conference (EPE/PEMC), 2012 15th International, 2012, pp. LS5a.1-1-LS5a.1-4.

[2] W. Qiu, Y. Yu, F. K. Tsang, and L. Sun, "A multifunctional, reconfigurable pulse generator for high-frequency ultrasound imaging," IEEE Transactions on Ultrasonics, Ferroelectrics, and Frequency Control, vol. 59, no. 7, pp. 1558-1567, 2012.

[3] J. A. Sabaté, R. R. Wang, F. Tao, and S. Chi, "Magnetic Resonance Imaging Power: High-Performance MVA Gradient Drivers," IEEE Journal of Emerging and Selected Topics in Power Electronics, vol. 4, no. 1, pp. 280-292, 2016.

[4] J. Sun, X. Ding, M. Nakaoka, and H. Takano, "Series resonant ZCS-PFM DC-DC converter with multistage rectified voltage multiplier and dual-mode PFM control scheme for medical-use high-voltage X-ray power generator," IEE Proceedings - Electric Power Applications, vol. 147, no. 6, pp. 527-534, 2000.

[5] J. Punter-Villagrasa et al., "A low-power electronic instrumentation for multi-parametric diabetes mellitus analysis," in IECON 2016 - 42nd Annual Conference of the IEEE Industrial Electronics Society, 2016, pp. 5211-5215.

[6] P. P. San, S. H. Ling, and H. T. Nguyen, "Industrial Application of Evolvable Block-Based Neural Network to Hypoglycemia Monitoring System," IEEE Transactions on Industrial Electronics, vol. 60, no. 12, pp. 5892-5901, 2013.

[7] J. L. Ristić-Djurović et al., "Design and Optimization of Electromagnets for Biomedical Experiments With Static Magnetic and ELF Electromagnetic Fields," IEEE Transactions on Industrial Electronics, vol. 65, no. 6, pp. 4991-5000, 2018.

[8] V. Blazek, P. S. Neelakantaswamy, and V. C. V. P. Reddy, "Generation of Complex Waveforms for Biomedical Application," IEEE Transactions on Biomedical Engineering, vol. BME-22, no. 6, pp. 535-536, 1975.

[9] P. Dario, E. Guglielmelli, B. Allotta, and M. C. Carrozza, "Robotics for medical applications," IEEE Robotics \& Automation Magazine, vol. 3, no. 3, pp. 44-56, 1996.

[10] P. Dario, B. Hannaford, and A. Menciassi, "Smart surgical tools and augmenting devices," IEEE Transactions on Robotics and Automation, vol. 19, no. 5, pp. 782-792, 2003.

[11] C. P. Hancock et al., "A New Wave in Electrosurgery : A Review of Existing and Introduction to New Radio-Frequency and Microwave Therapeutic Systems," IEEE Microwave Magazine, vol. 16, no. 2, pp. 14-30, 2015.

[12] D. A. Friedrichs, R. W. Erickson, and J. Gilbert, "A New Dual Current-Mode Controller Improves Power Regulation in Electrosurgical Generators," IEEE Transactions on Biomedical Circuits and Systems, vol. 6, no. 1, pp. 39-44, 2012.

[13] F. Sterzer, R. W. Paglione, J. Mendecki, E. Friedenthal, and C. Botstein, "Electronics in medicine: RF therapy for malignancy: Heating of malignant tissues (hyperthermia) by RF radiation presents a new tool in the arsenal of weapons against cancer," IEEE Spectrum, vol. 17, no. 12, pp. 32-37, 1980.

[14] M. Cavagnaro, C. Amabile, P. Bernardi, S. Pisa, and N. Tosoratti, "A Minimally Invasive Antenna for Microwave Ablation Therapies: Design, Performances, and Experimental Assessment," IEEE Transactions on Biomedical Engineering, vol. 58, no. 4, pp. 949-959, 2011.

[15] P. Huang et al., "A Controlled-Release Drug Delivery System on a Chip Using Electrolysis," IEEE Transactions on Industrial Electronics, vol. 59, no. 3, pp. 1578-1587, 2012.

[16] B. Smith, P. H. Peckham, M. W. Keith, and D. D. Roscoe, "An Externally Powered, Multichannel, Implantable Stimulator for Versatile Control of Paralyzed Muscle," IEEE Transactions on Biomedical Engineering, vol. BME-34, no. 7, pp. 499-508, 1987. 
[17] L. Becerra-Fajardo, M. Schmidbauer, and A. Ivorra, "Demonstration of $2 \mathrm{~mm}$ Thick Microcontrolled Injectable Stimulators Based on Rectification of High Frequency Current Bursts," IEEE Transactions on Neural Systems and Rehabilitation Engineering, vol. 25, no. 8, pp. 1343-1352, 2017.

[18] O. Lucía, P. Maussion, E. Dede, and J. M. Burdío, "Induction heating technology and its applications: Past developments, current technology, and future challenges," (in English), IEEE Transactions on Industrial Electronics, vol. 61, no. 5, pp. 2509-2520, May 2014.

[19] H. Sarnago, O. Lucia, and J. M. Burdío, "High frequency and power density gallium nitride based inverter for magneto fluid hyperthermia," in IEEE Annual Conference of the Industrial Electronics Society, 2016, pp. 5222-5225.

[20] V. Kumar and V. Kakkar, "Miniaturized Resonant Power Conversion for Implanted Medical Devices," IEEE Access, vol. 5, pp. 15859-15864, 2017.

[21] Y. Lin, Y. Lin, C. Chen, H. Chen, Y. Yang, and S. Lu, "A 0.5-V Biomedical System-on-a-Chip for Intrabody Communication System," IEEE Transactions on Industrial Electronics, vol. 58, no. 2, pp. 690-699, 2011.

[22] H. Kim, H. Hirayama, S. Kim, K. J. Han, R. Zhang, and J. Choi, "Review of Near-Field Wireless Power and Communication for Biomedical Applications," IEEE Access, vol. 5, pp. 21264-21285, 2017.

[23] T. Fukuda and N. Kubota, "An intelligent robotic system based on a fuzzy approach," Proceedings of the IEEE, vol. 87, no. 9, pp. 1448-1470, 1999.

[24] D. E. Mouzakis, D. Dimogianopoulos, and D. Giannikas, "Contact-Free Magnetoelastic Smart Microsensors With Stochastic Noise Filtering for Diagnosing Orthopedic Implant Failures," IEEE Transactions on Industrial Electronics, vol. 56, no. 4, pp. 1092-1100, 2009.

[25] A. Kim, M. Ochoa, R. Rahimi, and B. Ziaie, "New and Emerging Energy Sources for Implantable Wireless Microdevices," IEEE Access, vol. 3, pp. 89-98, 2015.

[26] S. Ahmed and V. Kakkar, "An Electret-Based Angular Electrostatic Energy Harvester for Battery-Less Cardiac and Neural Implants," IEEE Access, vol. 5, pp. 19631-19643, 2017

[27] M. R. Basar, M. Y. Ahmad, J. Cho, and F. Ibrahim, "An Improved Wearable Resonant Wireless Power Transfer System for Biomedical Capsule Endoscope," IEEE Transactions on Industrial Electronics, vol. 65, no. 10, pp. 7772-7781, 2018.

[28] D. Ahn and S. Hong, "Wireless Power Transmission With Self-Regulated Output Voltage for Biomedical Implant," IEEE Transactions on Industrial Electronics, vol. 61, no. 5, pp. 2225-2235, 2014.

[29] O. Knecht and J. W. Kolar, "Performance of Series-Compensated IPT Systems for High Power Transcutaneous Energy Transfer," IEEE Transactions on Power Electronics, pp. 1-1, 2018.

[30] O. Knecht, R. Bosshard, and J. W. Kolar, "High-Efficiency Transcutaneous Energy Transfer for Implantable Mechanical Heart Support Systems," IEEE Transactions on Power Electronics, vol. 30, no. 11, pp. 6221-6236, 2015.

[31] M. Meng and M. Kiani, "Design and Optimization of Ultrasonic Wireless Power Transmission Links for Millimeter-Sized Biomedical Implants," IEEE Transactions on Biomedical Circuits and Systems, vol. 11, no. 1, pp. 98-107, 2017.

[32] Y. Wang and D. Ma, "Design of Integrated Dual-Loop $<$ formula formulatype="inline" $><$ tex Notation="TeX" $>\$ \mid D e l t a \$</$ tex $></$ formula $>-<$ formula formulatype="inline" $><$ tex Notation="TeX" $>\$ \mid$ Sigma $\$</$ tex $></$ formula $>$ Modulated Switching Power Converter for Adaptive Wireless Powering in Biomedical Implants," IEEE Transactions on Industrial Electronics, vol. 58, no. 9, pp. 4241-4249, 2011.

[33] W. T. Ang, C. Scurtescu, W. Hoy, T. El-Bialy, Y. Y. Tsui, and J. Chen, "Design and Implementation of Therapeutic Ultrasound Generating Circuit for Dental Tissue Formation and Tooth-Root Healing," IEEE Transactions on Biomedical Circuits and Systems, vol. 4, no. 1, pp. 49-61, 2010.

[34] S. Ethier and M. Sawan, "Exponential Current Pulse Generation for Efficient Very High-Impedance Multisite Stimulation," IEEE Transactions on Biomedical Circuits and Systems, vol. 5, no. 1, pp. 30-38, 2011.

[35] N. R. Bouda, M. Mina, and R. J. Weber, "High-Current Magnetic Field Generator for Transcranial Magnetic Stimulation Applications," IEEE Transactions on Magnetics, vol. 50, no. 11, pp. 1-4, 2014.

[36] L. Guo, N. J. Kubat, and R. A. Isenberg, "Pulsed radio frequency energy (PRFE) use in human medical applications," (in eng), Electromagn Biol Med, vol. 30, no. 1, pp. 21-45, Mar 2011

[37] D. V. Palanker, A. Vankov, and P. Huie, "Electrosurgery With Cellular Precision," IEEE Transactions on Biomedical Engineering, vol. 55, no. 2, pp. 838$841,2008$.

[38] C. L. Hoy et al., "Clinical Ultrafast Laser Surgery: Recent Advances and Future Directions," IEEE Journal of Selected Topics in Quantum Electronics, vol. 20, no. 2, pp. 242-255, 2014.

[39] S. Russo, P. Dario, and A. Menciassi, "A Novel Robotic Platform for Laser-Assisted Transurethral Surgery of the Prostate," IEEE Transactions on Biomedical Engineering, vol. 62, no. 2, pp. 489-500, 2015.

[40] A. Rosen, M. A. Stuchly, and A. V. Vorst, "Applications of RF/microwaves in medicine," IEEE Transactions on Microwave Theory and Techniques, vol. 50, no. 3, pp. 963-974, 2002.

[41] T. Kotnik, P. Kramar, G. Pucihar, D. Miklavcic, and M. Tarek, "Cell membrane electroporation- Part 1: The phenomenon," IEEE Electrical Insulation Magazine, vol. 28, no. 5, pp. 14-23, 2012.

[42] T. Kotnik and D. Miklavcic, "Analytical description of transmembrane voltage induced by electric fields on spheroidal cells," (in eng), Biophysical journal, vol. 79, no. 2, pp. 670-679, 2000.

[43] M. Tarek, "Membrane Electroporation: A Molecular Dynamics Simulation," Biophysical Journal, vol. 88, no. 6, pp. 4045-4053, 2005/06/01/ 2005.

[44] H. Sarnago, O. Lucía, A. Naval, J. M. Burdío, Q. Castellví, and A. Ivorra, "A versatile multi-level converter platform for cancer treatment using irreversible electroporation," IEEE Journal on Emerging and Selected Topics in Power Electronics, vol. 4, no. 1, pp. 236-242, 2016.

[45] G. Pucihar et al., "Equivalent Pulse Parameters for Electroporation," IEEE Transactions on biomedical Engineering, vol. 58, no. 11, pp. 3279-3288, 2011.

[46] J. C. Weaver, K. C. Smith, A. T. Esser, R. S. Son, and T. R. Gowrishankar, "A brief overview of electroporation pulse strength-duration space: a region where additional intracellular effects are expected," (in eng), Bioelectrochemistry, vol. 87, pp. 236-43, Oct 2012.

[47] J. Chunlan, R. V. Davalos, and J. C. Bischof, "A Review of Basic to Clinical Studies of Irreversible Electroporation Therapy," IEEE Transactions on biomedical Engineering, vol. 62, no. 1, pp. 4-20, 2015.

[48] J. A. Nollet, Recherches sur les causes particulieres des phénoménes électriques: et sur les effets nuisibles ou avantageux qu'on peut en attendre. Chez les Freres Guerin, 1749.

[49] A. Ivorra and B. Rubinsky, "Historical Review of Irreversible Electroporation in Medicine," in Irreversible Electroporation, B. Rubinsky, Ed. (Series in Biomedical Engineering: Springer Berlin Heidelberg, 2010, pp. 1-21.

[50] R. J. Grasso, R. Heller, J. C. Cooley, and E. M. Haller, "Electroffusion of individual animal cells directly to intact corneal epithelial tissue," Biochimica et Biophysica Acta (BBA) - Biomembranes, vol. 980, no. 1, pp. 9-14, 1989/03/27/ 1989.

[51] L. M. Mir et al., "Electrochemotherapy, a new antitumor treatment: first clinical trial," (in fre), C R Acad Sci III, vol. 313, no. 13, pp. 613-8, 1991. L'electrochimiotherapie, un nouveau traitement antitumoral: premier essai clinique.

[52] L. M. Mir, S. Orlowski, J. Belehradek, Jr., and C. Paoletti, "Electrochemotherapy potentiation of antitumour effect of bleomy cin by local electric pulses," (in eng), Eur J Cancer, vol. 27, no. 1, pp. 68-72, 1991

[53] J. Belehradek, Jr., S. Orlowski, B. Poddevin, C. Paoletti, and L. M. Mir, "Electrochemotherapy of spontaneous mammary tumours in mice," European Journal of Cancer and Clinical Oncology, vol. 27, no. 1, pp. 73-76, 1991.

[54] D. Miklavcic et al., "Electrochemotherapy: technological advancements for efficient electroporation-based treatment of internal tumors," (in eng), Med Biol Eng Comput, vol. 50, no. 12, pp. 1213-25, Dec 2012. 
[55] C. Schultheiss, H. Bluhm, H. Mayer, M. Kern, T. Michelberger, and G. Witte, "Processing of sugar beets with pulsed-electric fields," IEEE Transactions on Plasma Science, vol. 30, no. 4, pp. 1547-1551, 2002.

[56] M. A. Elgenedy, A. Darwish, S. Ahmed, and B. W. Williams, "A Modular Multilevel-Based High-Voltage Pulse Generator for Water Disinfection Applications," IEEE Transactions on Plasma Science, vol. 44, no. 11, pp. 2893-2900, 2016.

[57] M. A. Elgenedy, A. M. Massoud, S. Ahmed, and B. W. Williams, "A High-Gain, High-Voltage Pulse Generator Using Sequentially Charged Modular Multilevel Converter Submodules, for Water Disinfection Applications," IEEE Journal of Emerging and Selected Topics in Power Electronics, vol. 6, no. 3, pp. 1394-1406, 2018.

[58] R. D. Jamieson, M. P. Bodger, P. S. Bodger, and D. Baran, "Transfection by electroporation: cell gene transfer using electrical impulses, a new process in blood cancer research," IEE Proceedings A - Physical Science, Measurement and Instrumentation, Management and Education, vol. 136, no. 1, pp. 41-44, 1989.

[59] M. Marty et al., "Electrochemotherapy - An easy, highly effective and safe treatment of cutaneous and subcutaneous metastases: Results of ESOPE (European Standard Operating Procedures of Electrochemotherapy) study," European Journal of Cancer, Supplement, Article vol. 4, no. 11, pp. 3-13, 2006.

[60] R. V. Davalos, L. M. Mir, and B. Rubinsky, "Tissue ablation with irreversible electroporation," Annals of Biomedical Engineering, vol. 33, no. 2, pp. 223$231,2005$.

[61] G. Bianchi, L. Campanacci, M. Ronchetti, and D. Donati, "Electrochemotherapy in the Treatment of Bone Metastases: A Phase II Trial," World Journal of Surgery, journal article vol. 40, no. 12, pp. 3088-3094, December 012016.

[62] A. M. Ierardi et al., "Percutaneous ablation therapies of inoperable pancreatic cancer: a systematic review," Annals of gastroenterology, vol. 28, no. 4, pp. 431-439, Oct-Dec 2015.

[63] B. Al-Sakere et al., "Tumor ablation with irreversible electroporation," PloS one, vol. 2, no. 11, pp. e1135-e1135, 2007.

[64] B. Al-Sakere et al., "A study of the immunological response to tumor ablation with irreversible electroporation," (in eng), Technol Cancer Res Treat, vol. 6, no. 4, pp. 301-6, Aug 2007.

[65] E. W. Lee, S. Thai, and S. T. Kee, "Irreversible electroporation: a novel image-guided cancer therapy," (in eng), Gut Liver, vol. 4 Suppl 1, pp. S99-s104, Sep 2010.

[66] H. J. Scheffer et al., "Irreversible electroporation for nonthermal tumor ablation in the clinical setting: a systematic review of safety and efficacy," (in eng), J Vasc Interv Radiol, vol. 25, no. 7, pp. 997-1011; quiz 1011, Jul 2014.

[67] J. P. Tasu et al., "Irreversible Electroporation for Locally Advanced Pancreatic Cancer: Where Do We Stand in 2017?," (in eng), Pancreas, vol. 46, no. 3, pp. 283-287, Mar 2017.

[68] C.-Y. Hsiao and K.-W. Huang, "Irreversible Electroporation: A Novel Ultrasound-guided Modality for Non-thermal Tumor Ablation," Journal of Medical Ultrasound, vol. 25, no. 4, pp. 195-200, 2017/12/01/2017.

[69] C. B. Arena et al., "High-frequency irreversible electroporation (H-FIRE) for non-thermal ablation without muscle contraction," Biomedical engineering online, vol. 10, pp. 102-102, 2011.

[70] L. M. Mir et al., "Standard operating procedures of the electrochemotherapy : Instructions for the use of bleomycin or cisplatin administered either systemically or locally and electric pulses delivered by the CliniporatorTM by means of invasive or non-invasive electrodes," Eur. J. of Cancer Supplements, vol. 4, pp. 14-25, 2006.

[71] J. Gehl et al., "Updated standard operating procedures for electrochemotherapy of cutaneous tumours and skin metastases," (in eng), Acta Oncol, vol. 57, no. 7, pp. 874-882, Jul 2018.

[72] G. Pron, J. Belehradek, Jr., and L. M. Mir, "Identification of a plasma membrane protein that specifically binds bleomycin," (in eng), Biochem Biophys Res Commun, vol. 194, no. 1, pp. 333-7, Jul 151993.

[73] C. Y. Calvet, D. Famin, F. M. Andre, and L. M. Mir, "Electrochemotherapy with bleomycin induces hallmarks of immunogenic cell death in murine colon cancer cells," (in eng), Oncoimmunology, vol. 3, p. e28131, 2014.

[74] C. Y. Calvet and L. M. Mir, "The promising alliance of anti-cancer electrochemotherapy with immunotherapy," (in eng), Cancer Metastasis Rev, vol. 35, no. 2, pp. 165-77, Jun 2016.

[75] M. Cemazar et al., "Electrochemotherapy in veterinary oncology," (in eng), J Vet Intern Med, vol. 22, no. 4, pp. 826-31, Jul-Aug 2008.

[76] S. Satkauskas, M. F. Bureau, A. Mahfoudi, and L. M. Mir, "Slow accumulation of plasmid in muscle cells: supporting evidence for a mechanism of DNA uptake by receptor-mediated endocytosis," (in eng), Mol Ther, vol. 4, no. 4, pp. 317-23, Oct 2001.

[77] M. P. Rols, C. Delteil, M. Golzio, P. Dumond, S. Cros, and J. Teissie, "In vivo electrically mediated protein and gene transfer in murine melanoma," (in eng), Nat Biotechnol, vol. 16, no. 2, pp. 168-71, Feb 1998.

[78] M. Bettan, M. A. Ivanov, L. M. Mir, F. Boissiere, P. Delaere, and D. Scherman, "Efficient DNA electrotransfer into tumors," (in eng), Bioelectrochemistry, vol. 52, no. 1, pp. 83-90, Sep 2000.

[79] A. I. Daud et al., "Phase I trial of interleukin-12 plasmid electroporation in patients with metastatic melanoma," (in eng), J Clin Oncol, vol. 26, no. 36, pp. 5896-903, Dec 202008.

[80] D. Pavlin, M. Cemazar, A. Cör, G. Sersa, A. Pogacnik, and N. Tozon, "Electrogene therapy with interleukin-12 in canine mast cell tumors," Radiology and oncology, vol. 45, no. 1, pp. 31-39, 2010.

[81] T. Tamura and T. Sakata, "Application of in vivo electroporation to cancer gene therapy," (in eng), Curr Gene Ther, vol. 3, no. 1, pp. 59-64, Feb 2003.

[82] G. Kichaev et al., "Electroporation mediated DNA vaccination directly to a mucosal surface results in improved immune responses," Human vaccines \& immunotherapeutics, vol. 9, no. 10, pp. 2041-2048, 2013.

[83] S. H. Lee, S. N. Danishmalik, and J. I. Sin, "DNA vaccines, electroporation and their applications in cancer treatment," (in eng), Hum Vaccin Immunother, vol. 11, no. 8, pp. 1889-900, 2015.

[84] M. Rebersek, D. Miklavcic, C. Bertacchini, and M. Sack, "Cell membrane electroporation-Part 3: the equipment," IEEE Electrical Insulation Magazine, vol. 30, no. 3, pp. 8-18, 2014.

[85] F. M. Andre et al., "Efficiency of high- and low-voltage pulse combinations for gene electrotransfer in muscle, liver, tumor, and skin," (in eng), Hum Gene Ther, vol. 19, no. 11, pp. 1261-71, Nov 2008.

[86] K. H. Schoenbach et al., "Bioelectric Effects of Intense Nanosecond Pulses," IEEE Transactions on Dielectrics and Electrical Insulation, vol. 14, no. 5, pp. 1088-1109, 2007.

[87] T. Kotnik, G. Pucihar, M. Reberšek, D. Miklavčič, and L. M. Mir, "Role of pulse shape in cell membrane electropermeabilization," Biochimica et Biophysica Acta (BBA) - Biomembranes, vol. 1614, no. 2, pp. 193-200, 2003/08/07/ 2003.

[88] S. Y. Tseng, T. F. Wu, H. R. Yang, J. C. Guo, and J. C. Hung, "Soft-switching series-resonant converter to generate high output voltage for processing microbes," in Applied Power Electronics Conference and Exposition, 2004. APEC '04. Nineteenth Annual IEEE, 2004, vol. 2, pp. $905-911$ vol.2.

[89] M. A. Elgenedy, A. Darwish, S. Ahmed, and B. W. Williams, "A Transition Arm Modular Multilevel Universal Pulse-Waveform Generator for Electroporation Applications," IEEE Transactions on Power Electronics, vol. 32, no. 12, pp. 8979-8991, 2017.

[90] M. A. Elgenedy, A. Darwish, S. Ahmed, and B. W. Williams, "A Modular Multilevel Generic Pulse-Waveform Generator for Pulsed Electric Field Applications," IEEE Transactions on Plasma Science, vol. 45, no. 9, pp. 2527-2535, 2017. 
[91] M. Petkovsek, J. Nastran, D. Voncina, P. Zajec, D. Miklavcic, and G. Sersa, "High voltage pulse generation [electroporation]," Electronics Letters, vol. 38, no. 14 , pp. 680-682, 2002.

[92] S. Kohler, V. Couderc, R. P. O. Connor, D. Arnaud-Cormos, and P. Leveque, "A versatile high voltage nano- and sub-nanosecond pulse generator," IEEE Transactions on Dielectrics and Electrical Insulation, vol. 20, no. 4, pp. 1201-1208, 2013.

[93] T. Tang, F. Wang, A. Kuthi, and M. A. Gundersen, "Diode Opening Switch Based Nanosecond High Voltage Pulse Generators for Biological and Medical Applications," IEEE Transactions on Dielectrics and Electrical Insulation, vol. 14, no. 4, pp. 878-883, 2007.

[94] M. Rebersek et al., "Blumlein Configuration for High-Repetition-Rate Pulse Generation of Variable Duration and Polarity Using Synchronized Switch Control," IEEE Transactions on Biomedical Engineering, vol. 56, no. 11, pp. 2642-2648, 2009.

[95] L. G. Staal and R. Gilbert, "Generators and Applicators: Equipment for Electroporation," in Clinical aspects of Electroporation, Springer, Ed., 2011, pp. 45-65.

[96] C. Bertacchini, P. M. Margotti, E. Bergamini, A. Lodi, M. Ronchetti, and R. Cadossi, "Design of an irreversible electroporation system for clinical use," (in eng), Technol Cancer Res Treat, vol. 6, no. 4, pp. 313-20, Aug 2007.

[97] T. Garcia-Sanchez et al., "Successful tumor Electrochemotherapy using Sine Waves," IEEE Transactions on Biomedical Engineering, pp. 1-1, 2019.

[98] B. López-Alonso et al., "Histopathological and Ultrastructural Changes after Electroporation in Pig Liver Using Parallel-Plate Electrodes and HighPerformance Generator," Scientific Reports, vol. 9, no. 1, p. 2647, 2019.

[99] S. J. E. Rombouts et al., "Irreversible Electroporation of the Pancreas Using Parallel Plate Electrodes in a Porcine Model: A Feasibility Study," PLOS ONE, vol. 12, no. 1, p. e0169396, 2017.

[100] L. G. Campana, F. Dughiero, M. Forzan, R. Rizzo, and E. Sieni, "Analysis of the effect of not-parallel needles in electroporation," in 2016 IEEE Conference on Electromagnetic Field Computation (CEFC), 2016, pp. 1-1.

[101] L. G. Campana, P. D. Barba, F. Dughiero, C. R. Rossi, and E. Sieni, "Optimal Needle Positioning for Electrochemotherapy: A Constrained Multiobjective Strategy," IEEE Transactions on Magnetics, vol. 49, no. 5, pp. 2141-2144, 2013.

[102] S. B. Dev, D. Dhar, and W. Krassowska, "Electric field of a six-needle array electrode used in drug and DNA delivery in vivo: analytical versus numerical solution," IEEE Transactions on Biomedical Engineering, vol. 50, no. 11, pp. 1296-1300, 2003.

[103] F. Dughiero, E. Sieni, L. Biasiolo, L. G. Campana, and P. F. Bariani, "Applicator and apparatus for electroporation," WO2019053600, 2019.

[104] K. Kurata, S. Yoshimatsu, and H. Takamatsu, "Low-Voltage Irreversible Electroporation Using a Comb-Shaped Contact Electrode," IEEE Transactions on Biomedical Engineering, pp. 1-1, 2019.

[105] A. Wandel et al., "Optimizing Irreversible Electroporation Ablation with a Bipolar Electrode," Journal of Vascular and Interventional Radiology, vol. 27, no. 9, pp. 1441-1450.e2, 2016/09/01/2016.

[106] H. Sarnago, J. M. Burdío, T. García-Sánchez, L. M. Mir, and O. Lucía, "A Versatile Large-Signal High-Frequency Arbitrary Waveform Generator Using GaN Devices," in IEEE Applied Power Electronics Conference and Exposition, 2019, pp. 458-462.

[107] M. A. Elgenedy, A. Massoud, S. Ahmed, B. Williams, and J. McDonald, "A Modular Multilevel Voltage-Boosting Marx Pulse-Waveform Generator for Electroporation Applications," IEEE Transactions on Power Electronics, pp. 1-1, 2019.

[108] E. Pirc, D. Miklavcic, and M. Rebersek, "Nanosecond Pulse Electroporator with Silicon Carbide MOSFETs, Development and Evaluation," IEEE Transactions on Biomedical Engineering, pp. 1-1, 2019.

[109] M. C. Junquera et al., "Electron microscope evaluation of irreversible electroporation on the liver in a porcine model," Histology and Histopathology, vol. 32, no. Suplement 1, p. 125, 2017.

[110] B. Rubinsky, "Irreversible electroporation in medicine," (in eng), Technol Cancer Res Treat, vol. 6, no. 4, pp. $255-60$, Aug 2007.

[111] L. J. Savic, J. Chapiro, B. Hamm, B. Gebauer, and F. Collettini, "Irreversible Electroporation in Interventional Oncology: Where We Stand and Where We Go," (in De), Fortschr Röntgenstr, vol. 188, no. 08, pp. 735-745, //

26.07.2016 2016.

[112] M. L. Yarmush, A. Golberg, G. Sersa, T. Kotnik, and D. Miklavcic, "Electroporation-based technologies for medicine: principles, applications, and challenges," (in eng), Аnпи Rev Biomed Eng, vol. 16, pp. 295-320, Jul 112014.

[113] X. She, A. Q. Huang, O. Lucia, and B. Ozpineci, "Review of Silicon Carbide Power Devices and Their Applications," (in English), IEEE Transactions on Industrial Electronics, vol. 64, no. 10, pp. 8193-8205, Oct 2017.

[114] O. Lucía, E. Monmasson, D. Navarro, L. A. Barragán, I. Urriza, and J. I. Artigas, "Modern control architectures and implementation," in Control of Power Electronic Converters and Systems, vol. 2, F. Blaabjerg, Ed. 1 ed. USA: Elsevier, 2018. 